Summary: Hydroxyapatite, chitosan, and aliphatic polyester were compounded using a twin-screw extruder. The polyesters include poly( $\varepsilon$-caprolactone) (PCL), poly(lactic acid), poly(butylene succinate) (PBS), and poly(butylene terephthalate adipate). The mass fraction of chitosan ranged from 17.5 to $45 \%$, while that of HA ranged from 10 to $30 \%$. These blends were injection molded and evaluated for thermal, morphological, and mechanical properties. The addition of hydroxyapatite decreased the crystallinity in chitosan/PBS blends, while in blends containing chitosan/PCL, the crystallinity increased. Addition of hydroxyapatite significantly decreased the tensile strength and elongation of polyester/ hydroxyapatite composites as well as chitosan/polyester/ hydroxyapatite composites with elongations undergoing decreases over an order of magnitude. The tensile strength of the composite was dictated by the adhesion of HA to the chitosan/polyester matrix. The tensile strength of composites containing hydroxyapatite could be predicted using the Nicolai and Narkis equation for weak filler adhesion $(K \approx 1.21)$. Tensile-fractured and cryogenically-fractured surface indicates extensive debonding of hydroxyapatite crystals from the matrix, indicating weak adhesion. The adhe- sion of hydroxyapatite was higher for pure polyester than those containing chitosan and polyester. The modulus of the composites registered modest increase. The two main diffraction peaks observed using WAXS are unaffected by the amount of chitosan or hydroxyapatite.

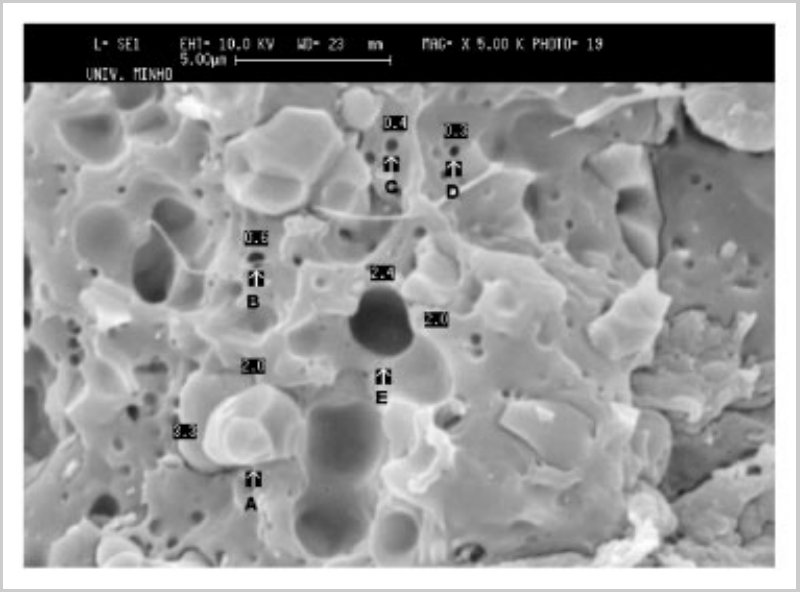

\title{
Hydroxyapatite Reinforced Chitosan and Polyester Blends for Biomedical Applications
}

\author{
Vitor M. Correlo, ${ }^{1}$ Luciano F. Boesel, ${ }^{1}$ Mrinal Bhattacharya,${ }^{* 2}$ Joao F. Mano, ${ }^{1}$ Nuno M. Neves, ${ }^{1}$ Ruis L. Reis ${ }^{1}$ \\ ${ }^{1}$ 3B's Research Group - Biomaterials, Biodegradable and Biomimetics, Department of Polymer Engineering, University of Minho, \\ Campus de Gualtar, 4710-057 Portugal \\ ${ }^{2}$ Department of Biosystems Engineering, University of Minnesota, St. Paul, MN 55108, USA \\ E-mail: bhatt002@umn.edu
}

Received: April 15, 2005; Revised: July 27, 2005; Accepted: October 6, 2005; DOI: 10.1002/mame.200500163

Keywords: composites; mechanical properties; polyesters; processing; thermal properties

\section{Introduction}

Chitin, an unbranched polysaccharide derived from the exoskeletons of crustaceans, insects, and mollusks, and the cell walls of microorganisms ${ }^{[1]}$ is finding increased use in biomedical applications. Chitosan, a linear amino polysaccharide obtained by de-acetylation of chitin, and chitin possesses the inherent physical and biological characteristics that may render them useful as a component in hard tissue replacement material. Chitin's role in the exoskeleton of crustaceans is analogous to that of collagen in bone, being the fibrous matrix acting as template for the devel- opment of inorganic calcium material. Due to their good biological activity (providing affinity and surface chemistry ideal for contact with cells), biocompatibility, and biodegradability, chitosan and its derivatives have attracted attention for potential applications in the field of biomedical polymers. ${ }^{[2]}$ These biomolecules have been reported to have applications as anticoagulants, wound-healing accelerators, wound dressing, artificial bone, and in drug delivery systems. ${ }^{[3]}$

A large number of synthetic polymers have found varying uses in biomedical industries. These are summarized in several monographs, symposium proceedings, and texts. ${ }^{[4,5]}$ 
While naturally occurring polymers exhibit a range of properties that make them suitable for use as alternatives to currently used biomaterials, they have less than ideal mechanical properties which precludes their use as materials in load bearing applications. The development of hybrid materials that combine naturally occurring polymers with biocompatible synthetic polymers is expected to minimize the mismatch of mechanical properties and preserve biocompatibility.

Hydroxyapatite (HA) is often added to orthopedic devices to induce osteoconductivity or bone-bonding ability. Few, if any, synthetic polymers are osteoconductive. Hydroxyapatite, because of its similar chemical structure to the inorganic composition of human bone, is often used in bone reconstruction. Several studies have shown the bone bonding ability of HA. ${ }^{[6-8]}$ Hydroxyapatite has also been evaluated as a reinforcing agent with polymers such as HDPE, ${ }^{[9-11]}$ PLLA, ${ }^{[12]}$ PMMA,${ }^{[13-15]}$ PHB homopolymer and $\mathrm{P}(\mathrm{HB}-\mathrm{HV})$ copolymers, ${ }^{[16,17]}$ starch, ${ }^{[18,19]}$ and polyester-ether ${ }^{[20]}$ to form bioactive compounds. In addition to increasing the modulus, apatites have biocompatibility with several cell types such as osteoblasts, osteoclasts, fibroblasts, and periodontal ligament cells that are found in calcified tissues. ${ }^{[21-23]}$

In an earlier paper, ${ }^{[24]}$ we reported on the properties of composites of chitosan and aliphatic polyesters. The objective of this research was to evaluate the properties of hydroxyapatite, chitosan, and biodegradable aliphatic polyesters (poly( $\varepsilon$-caprolactone) (PCL), poly(lactic acid) (PLA), poly(butylene succinate) (PBS), and poly(butylene terephthalate adipate) (PBTA). The tensile properties (tensile strength and tensile modulus), thermal properties, and morphological properties of the blends were evaluated. Ternary blends often lead to complex morphology and affect properties.

\section{Experimental Part}

\section{Materials}

The chitosan, supplied by France Chitin, (Orange, France), had a degree of deacetylation of approximately $85 \%$. The
Table 1. Material properties of polyesters used in this study.

\begin{tabular}{lcccc}
\hline & PCL 787 & PBS & PBTA & PLA \\
\hline Melt index & 4 & 50 & 20 & - \\
$\bar{M}_{\mathrm{n}} / 10^{5}$ & 0.64 & 0.34 & 0.43 & 1.54 \\
$\bar{M}_{\mathrm{w}} / 10^{5}$ & 1.24 & 0.89 & 0.78 & 2.52
\end{tabular}

polyesters used include poly( $\varepsilon$-caprolactone) (PCL), Poly(butylene succinate) (PBS), poly(lactic acid) (PLA), and poly(butylene terephthalate adipate) (PBTA). Polycaprolactone resin PCL 787, commercially available as $\mathrm{TONE}^{\mathrm{TM}}$ Polymer, was obtained from Union Carbide Chemicals and Plastics Division, Bound Brook, New Jersey. Eastar Bio Copolyester $14766^{\mathrm{TM}}$, a butanediol, adipate, and terephthalate copolymer, was obtained from Eastman Chemical Company, Kingsport, Tennessee. Bionolle ${ }^{\mathrm{TM}} 1050$, a polybutylene succinate copolymer, was obtained from Showa Highpolymer Co. Ltd., Tokyo, Japan. The characteristics of the various polyesters are summarized in Table 1. Hydroxyapatite (grade Capital S) $[3 \mu \mathrm{m}<d<6 \mu \mathrm{m}]$ was obtained from Plasma Biotal Ltd, Tideswell, England.

\section{Processing}

The materials processed and their composition is shown in Table 2. The composites were compounded in a co-rotating twin-screw extruder [Leistriz LSM 36]. Higher filler content pushed the torque in the extruder close to the maximum. Hence, each composition had $5 \%$ by weight of plasticizer (glycerol) to reduce the torque. The extruded strands were ground by a Coloritron grinder using $5 \mathrm{~mm}$ diameter pellets. The resulting composite were injection molded using an ENGEL injection moulding machine to produce tensile test bars. The tensile bars had a neck cross-section area of $2 \times$ $4 \mathrm{~mm}^{2}$ and a neck length of $20 \mathrm{~mm}$. The conditions used for moulding are summarized in Table 3.

\section{Mechanical Properties}

The tensile properties were determined using a Universal tensile testing machine (Instron 4505 Universal Machine). Tensile stress was taken as the maximum stress in the stressstrain curve. Tensile modulus was estimated from the initial slope of the stress strain curve. Samples were conditioned at

Table 2. Processing condition used for various blend and composite composition studied.

\begin{tabular}{|c|c|c|c|c|}
\hline \multirow[t]{3}{*}{ Material } & \multicolumn{4}{|c|}{ Processing conditions } \\
\hline & Temperature profile & Screw speed & Die temperature & Type of machine used \\
\hline & ${ }^{\circ} \mathrm{C}$ & $\mathrm{rpm}$ & ${ }^{\circ} \mathrm{C}$ & \\
\hline $70 \mathrm{PBS} / 30 \mathrm{HA}$ & $80 / 120 / 140 / 150 / 165 / 175$ & 100 & - & Co-rotating(LEISTRITZ) \\
\hline $17.5 \mathrm{C} / 52.5 \mathrm{PBS} / 30 \mathrm{HA}+5 \%$ glycerol & $80 / 120 / 140 / 150 / 165 / 175$ & 100 & - & Co-rotating(LEISTRITZ) \\
\hline $45 \mathrm{C} / 45 \mathrm{PBS} / 10 \mathrm{HA}+5 \%$ glycerol & $80 / 120 / 140 / 150 / 165 / 175$ & 100 & - & Co-rotating(LEISTRITZ) \\
\hline $40 \mathrm{C} / 40 \mathrm{PBS} / 20 \mathrm{HA}+5 \%$ glycerol & $80 / 120 / 140 / 150 / 165 / 175$ & 100 & - & Co-rotating(LEISTRITZ) \\
\hline $35 \mathrm{C} / 35 \mathrm{PBS} / 30 \mathrm{HA}+5 \%$ glycerol & $80 / 120 / 140 / 150 / 165 / 175$ & 100 & - & Co-rotating(LEISTRITZ) \\
\hline $35 \mathrm{C} / 35 \mathrm{PBTA} / 30 \mathrm{HA}+5 \%$ glycerol & $80 / 120 / 140 / 150 / 165 / 175$ & 100 & - & Co-rotating(LEISTRITZ) \\
\hline $35 \mathrm{C} / 35 \mathrm{PCL} / 30 \mathrm{HA}+5 \%$ glycerol & $80 / 120 / 140 / 150 / 165 / 175$ & 100 & - & Co-rotating(LEISTRITZ) \\
\hline $35 \mathrm{C} / 35 \mathrm{PLA} / 30 \mathrm{HA}+5 \%$ glycerol & $\begin{array}{l}175 \text { in first } 4 \text { zones, } 180 \\
\text { rest of the zones }\end{array}$ & 100 & 180 & Co-rotating(LEISTRITZ) \\
\hline
\end{tabular}


Table 3. Injection molding processing conditions for blends and composites.

\begin{tabular}{|c|c|c|c|}
\hline \multirow[t]{2}{*}{ Material } & Injection speed & \multirow{2}{*}{$\frac{\text { Holding pressure }}{\text { bar }}$} & \multirow{2}{*}{$\begin{array}{c}\text { Barrel temp. } \\
{ }^{\circ} \mathrm{C}\end{array}$} \\
\hline & $\mathrm{mm} / \mathrm{s}$ & & \\
\hline 70PBS/30HA & 28 & 40 & $90-120-120-140$ \\
\hline $17.5 \mathrm{C} / 52.5 \mathrm{PBS} / 30 \mathrm{HA}+5 \%$ glycerol & 28 & 20 & $110-130-150-160$ \\
\hline $45 \mathrm{C} / 45 \mathrm{PBS} / 10 \mathrm{HA}+5 \%$ glycerol & 26 & 20 & $110-130-150-160$ \\
\hline $40 \mathrm{C} / 40 \mathrm{PBS} / 20 \mathrm{HA}+5 \%$ glycerol & 32 & 20 & $110-130-150-160$ \\
\hline $35 \mathrm{C} / 35 \mathrm{PBS} / 30 \mathrm{HA}+5 \%$ glycerol & 30 & 20 & $110-130-150-160$ \\
\hline $35 \mathrm{C} / 35 \mathrm{PBTA} / 30 \mathrm{HA}+5 \%$ glycerol & 22 & 25 & $110-130-150-160$ \\
\hline $35 \mathrm{C} / 35 \mathrm{PCL} / 30 \mathrm{HA}+5 \%$ glycerol & 42 & 20 & $110-130-150-160$ \\
\hline
\end{tabular}

room temperature for at least $48 \mathrm{~h}$ before testing. A crosshead speed of $5 \mathrm{~mm} / \mathrm{min}$ was used. The values reported were the average of at least five specimens.

\section{Differential Scanning Calorimetry}

The DSC experiments were performed in a Perkin-Elmer DSC7 apparatus, using a water cooling accessory and nitrogen as a purge gas (flux gas of ca. $20 \mathrm{~cm}^{3} \cdot \mathrm{min}^{-1}$ ). Both temperature and heat flux were calibrated with Indium ( $99.99999 \%$ purity) at a scanning rate of $20^{\circ} \mathrm{C} / \mathrm{min}$. The samples were obtained by cutting a small piece of material (with ca. $10 \mathrm{mg}$ weight) in the central region of the injection parts. An effort was made to maintain the geometry of the different samples in order to keep the same thermal resistance. All the experiments were performed at $20^{\circ} \mathrm{C} / \mathrm{min}$, starting from room temperature. Only the first run was analyzed, which reflects not only the materials contained in the samples, but also the general morphology developed during processing.

\section{Wide-Angle X-Ray Scattering (WAXS)}

WAXS experiments were performed using X-ray synchrotron radiation (transmission mode) at the Soft Condensed Matter A2 beamline at the HASYLAB (DESY) synchrotron facility in Hamburg, Germany. The experimental setup included a linear detector for 1-D WAXS measurements (distance $23 \mathrm{~cm}$ ). $\mathrm{Cu} K_{\alpha}$ radiation, with a wavelength of $\lambda=0.154 \mathrm{~nm}$, was employed in the experiments. The injection moulded samples were fixed vertically, and the patterns were acquired at room temperature.

\section{Scanning Electron Microscopy}

The morphological characterization of the composites was made using a Leica-Cambridge S-360 scanning electron microscope. All the samples were sputter-coated with gold. Several different analyses of the cross-section of the tensile bars were made. These include (i) observations of fractured surfaces after break during the tensile tests and (ii) observations after immersing the samples in liquid nitrogen for one minute and fracturing the sample in the testing zone to analyze the brittle fracture of the composite.

\section{Results and Discussions}

\section{Differential Scanning Calorimetry}

Figure 1a shows the DSC scans of the 50/50 wt of chitosan and PLA blend. The glass transition at $60.1^{\circ} \mathrm{C}$ (midpoint) can be easily observed, together with the typical structural relaxation endothermic peak, the exothermic peak corresponding to the cold crystallization process (onset at $T_{\mathrm{c}}=89.2^{\circ} \mathrm{C}$ ) and melting peak, with an onset temperature of $155.7^{\circ} \mathrm{C}$. With the addition of $30 \%$ wt of HA in the blend, a drop on $T_{\mathrm{g}}\left(53.6^{\circ} \mathrm{C}\right)$ was observed. This may be attributed to an extended chain scission during the processing of the composite (HA/chitosan/PLA), with respect to the blend
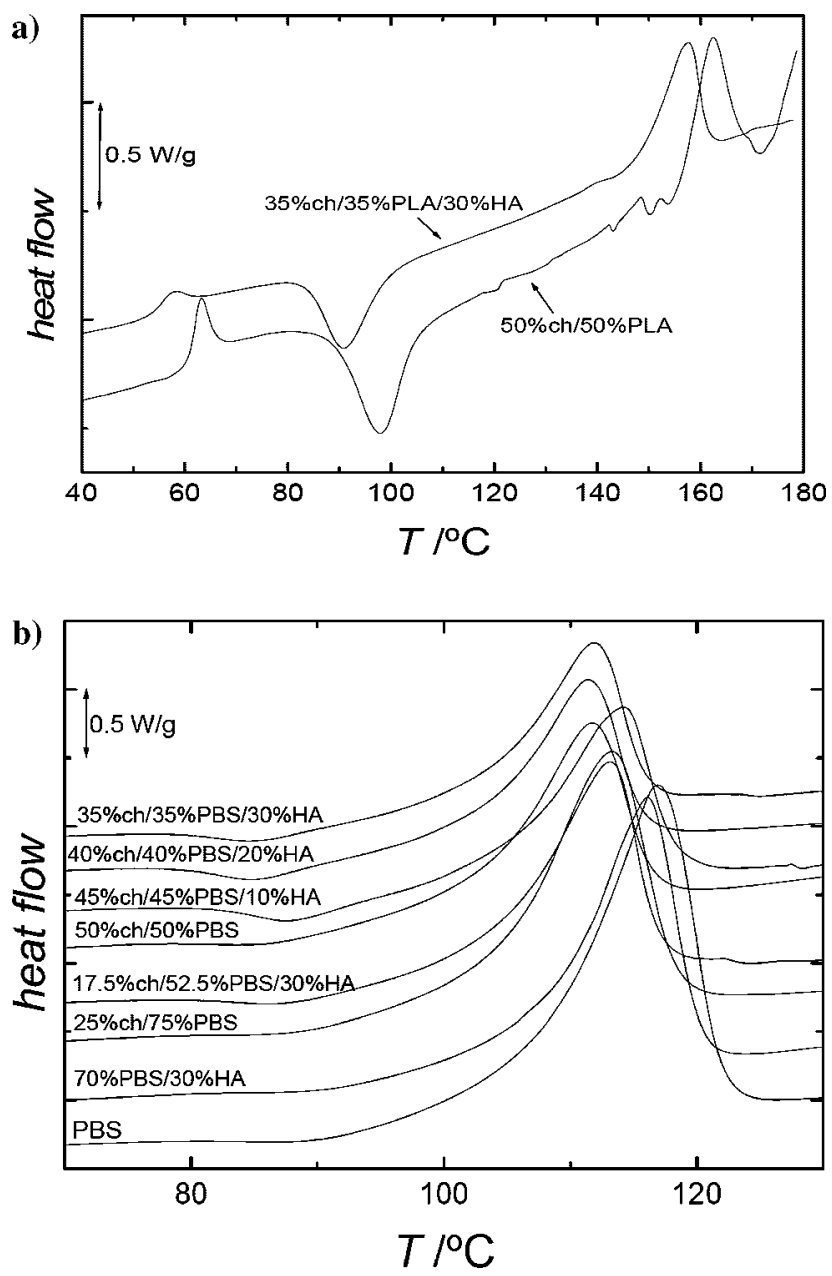

Figure 1. Representative DSC thermograms, obtained at $20^{\circ} \mathrm{C} \cdot \mathrm{min}^{-1}$, analyzing the effect of HA addition in (a) PLA and (b) PBS-based materials. 
Table 4. Melting temperature and heat of fusion of the different samples analyzed by DSC, and the corresponding crystallinity degree within the synthetic polymer component.

\begin{tabular}{|c|c|c|c|}
\hline \multirow[t]{2}{*}{ Sample } & $T_{\mathrm{m}}$ & $\Delta H$ & $X^{\text {a) }}$ \\
\hline & ${ }^{\circ} \mathrm{C}$ & $\mathrm{J} \cdot \mathrm{g}^{-1}$ & $\%$ \\
\hline $50 \% \mathrm{C}+50 \% \mathrm{PCL}$ & 55.2 & 25.9 & 31.2 \\
\hline $35 \% \mathrm{C}+35 \% \mathrm{PCL}+30 \% \mathrm{HA}$ & 53.5 & 20.9 & 36.0 \\
\hline PBS & 107.2 & 73 & 66.2 \\
\hline $70 \% \mathrm{PBS}+30 \% \mathrm{HA}$ & 107.9 & 49.9 & 64.6 \\
\hline $25 \% \mathrm{C}+75 \% \mathrm{PBS}$ & 103.4 & 55.5 & 67.1 \\
\hline $17.5 \% \mathrm{C}+52.5 \% \mathrm{PBS}+30 \% \mathrm{HA}$ & 103.7 & 39.1 & 67.5 \\
\hline $50 \% \mathrm{C}+50 \% \mathrm{PBS}$ & 102.4 & 31.7 & 57.5 \\
\hline $45 \% \mathrm{C}+45 \% \mathrm{PBS}+10 \% \mathrm{HA}$ & 104.6 & 33.5 & 67.5 \\
\hline $40 \% \mathrm{C}+40 \% \mathrm{PBS}+20 \% \mathrm{HA}$ & 103.1 & 28.7 & 65.0 \\
\hline $35 \% \mathrm{C}+35 \% \mathrm{PBS}+30 \% \mathrm{HA}$ & 102.9 & 30 & 77.7 \\
\hline
\end{tabular}

(chitosan/PLA). This may help explain the decrease of the cold-crystallization temperature $\left(T_{\mathrm{c}}=83.9^{\circ} \mathrm{C}\right)$ that is also observed upon the introduction of the HA. However, we believe that the HA particles play an important role as nucleating agents. In fact, it has been reported that composites of PLA/HA produced by solvent casting (where chances of thermal degradation are minimal) exhibit decreasing $T_{\mathrm{c}}$ with increasing HA content. ${ }^{[25]}$ Finally, the composite presents a lower melting temperature $\left(T_{\mathrm{m}}=148.2^{\circ} \mathrm{C}\right)$ than the pure PLA $\left(155.3^{\circ} \mathrm{C}^{[26]}\right)$. The presence of the HA particles during the cold-crystallization process could lead to the formation of less perfect crystalline structures, that melt at a lower temperatures.

A similar study was performed for the PCL system, where the 50/50 wt.-\% chitosan/PCL blend was reinforced with 30\%wt HA. In the DSC scans (figure not shown), the melting peak is clearly detected. The inclusion of hydroxyapatite decreased the melting temperature of the 50/ 50 wt.-\% chitosan/PCL blend (Table 4). Similar results were reported for PCL reinforced with hydroxyapatite nanocrystals, processed by solvent casting. ${ }^{[27]}$ From the enthalpy values, the degree of crystallinity of the PCL component in the samples was calculated from the known PCL content and by assuming that the heat of fusion of completely crystalline PCL is $166 \mathrm{~J} \cdot \mathrm{g}^{-1} \cdot{ }^{[28]}$ The reinforcement of chitosan/PCL by HA increased the degree of crystallinity in the PCL fraction (Table 4). In this case, the nucleating effect of the HA particles may be the origin of the enhancement of the degree of crystallization.

The DSC thermograms for the PBS-based materials are shown in Figure 1b. Again, the degree of crystallinity of the PBS component was calculated from the known theoretical value of $\Delta H_{\mathrm{m}}$ for $100 \%$ crystalline PBS, that was estimated to be $110.3 \mathrm{~J} \cdot \mathrm{g}^{-1}$, calculated on the basis of the group contribution method proposed by Van Krevelen. ${ }^{[29]}$ For PBS and all the blends with chitosan, the introduction of $30 \%$ of HA tends to increase the (onset) melting temper- ature (Table 4). This behavior is different from that found in PCL. The effect of the increase of HA content was analyzed for the composite with the same amount of PBS and chitosan. Interestingly, the increase of HA from 10 to $30 \%$ tends to decrease $T_{\mathrm{m}}$ (Table 4). This behavior indicates that a significant increase in $T_{\mathrm{m}}$ is found with the introduction of a low quantity of HA into the PBS-system, but with a further HA content the melt temperature systematically decreases. An explanation for this finding may be linked to the enhancing of molecular scission upon processing with the increase of the HA content. The degradation of polyester due to the presence of moisture and shear is well documented. ${ }^{[30,31]}$ As the HA content in the blend increased, the torque and hence the shear stresses increased leading to chain scission of the PBS. A more careful and controlled study is needed to fully elucidate this issue. The introduction of $30 \%$ of HA may influence the degree of crystallinity in the PBS fraction: it decreased slightly for pure PBS, increased slightly in the blend of PBS with 25 wt.- $\%$ chitosan, and finally increased significantly in the blend of PBS with $50 \%$ by weight chitosan (reflected in the reduction of the elastic modulus of this composite with respect to the un-reinforced blend). This indicates that the effect of HA may be dependent on the amount of polysaccharide in the blend. For the particular blend of 50/50\%wt chitosan/ PBS, the increase of the HA content tends to increase the degree of crystallinity, but the evolution is not progressive. Again, this behavior may be due to the decrease of the molecular weight of PBS during processing with increasing HA.

\section{Mechanical Properties}

The processing parameters for compounding and injection moulding are summarized in Table 2 and 3. It is well known that extrusion compounding parameters such as screw profile, barrel temperature, and residence time affect the morphology of blends. Similarly, several injection moulding processing parameters, such as injection speed, packing pressure, barrel temperature and mould temperature, may affect the tensile properties. In this study, no attempt was made to optimize properties. Rather, the conditions were selected for ease of processing and visual acceptance of molded parts.

The mechanical properties of composites containing hydroxyapatite with blends of chitosan and various polyesters are summarized in Table 5. Composites containing chitosan, PLA, and hydroxyapatite in the weight ratio of 35:35:30 were also compounded. However, these composites could not be moulded because of their inherent brittleness. The stress-strain behavior is shown in Figure 2. The ductility was low, and the composites were brittle. For the low filler content $(17.5 \% \mathrm{C} / 52.5 \% \mathrm{PBS} / 30 \% \mathrm{HA})$, the samples strain at constant stress before failing. Addition of hydroxyapatite increased the filler content of the composite 
Table 5. Tensile properties of various chitosan polyester blends with hydroxyapatites.

\begin{tabular}{|c|c|c|c|}
\hline \multirow[t]{2}{*}{ Materials } & Tensile strength & Tensile modulus & Elongation \\
\hline & $\mathrm{MPa}$ & $\mathrm{GPa}$ & $\%$ \\
\hline PBS & $38.6 \pm 1.3$ & $0.61 \pm 0.01$ & $264 \pm 29$ \\
\hline PCL & $27.3 \pm 0.8$ & $0.378 \pm 0.016$ & $674 \pm 36$ \\
\hline PBTA & $20.2 \pm 0.3$ & $0.0817 \pm 0.0011$ & $1075 \pm 37$ \\
\hline $70 \% \mathrm{PBS}+30 \% \mathrm{HA}$ & $28.3 \pm 0.2$ & $1.04 \pm 0.03$ & $13.12 \pm 1.74$ \\
\hline $17.5 \% \mathrm{C}+52.5 \% \mathrm{PBS}+30 \% \mathrm{HA}$ & $13.0 \pm 0.5$ & $1.05 \pm 0.07$ & $4.35 \pm 0.16$ \\
\hline $45 \% \mathrm{C}+45 \% \mathrm{PBS}+10 \% \mathrm{HA}$ & $15.9 \pm 0.6$ & $1.85 \pm 0.03$ & $1.56 \pm 0.2$ \\
\hline $40 \% \mathrm{C}+40 \% \mathrm{BS}+20 \% \mathrm{HA}$ & $12.1 \pm 3.2$ & $1.95 \pm 0.03$ & $1.00 \pm 0.34$ \\
\hline $35 \% \mathrm{C}+35 \% \mathrm{PBS}+30 \% \mathrm{HA}$ & $13.1 \pm 1.4$ & $1.81 \pm 0.08$ & $1.18 \pm 0.21$ \\
\hline $35 \% \mathrm{C}+35 \%$ PBTA $+30 \% \mathrm{HA}$ & $11.2 \pm 0.4$ & $0.71 \pm 0.03$ & $3.25 \pm 0.24$ \\
\hline $35 \% \mathrm{C}+35 \% \mathrm{PCL}+30 \% \mathrm{HA}$ & $14.6 \pm 0.8$ & $1.45 \pm 0.05$ & $1.67 \pm 0.18$ \\
\hline
\end{tabular}

and further decreased the tensile strength over chitosan/ polyester blends. ${ }^{[2]}$ The addition of chitosan to polyesters caused a modest decrease $(\approx 20 \%$ for $50 \%$ chitosan in the blend) in the tensile strength and significant increase in the modulus ( $\approx 3$-fold). Similar results have been reported by others in the literature. ${ }^{[15,17,20]}$ This is due to incompatibility between the components of the composites that gives rise to low interphase adhesion between the matrix and the dispersed phase, particularly the adhesion of hydroxyapatite to either chitosan or polyester.

The elongation at break shows a marked decrease upon the addition of hydroxapatite (Table 5). There is approximately a two orders of magnitude decrease in the elongation at break upon the addition of $30 \%$ hydroxyapatite to the polyester. While the pure polyesters underwent plastic deformation, the composites displayed brittle failure. According to Dubnikova et al., ${ }^{[32]}$ there is a critical filler volume fraction $(\phi)$ below which the samples deform by necking.

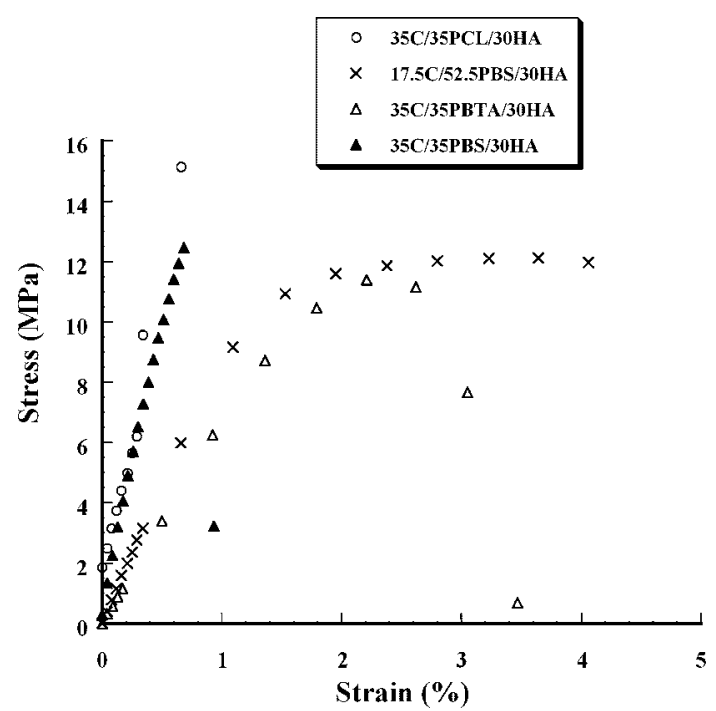

Figure 2. Stress versus strain curves for chitosan, polyester and hydroxyapatite composites.
Beyond this critical value, there is negligible shrinkage of the cross-sectional area when deformation occurs.

Predictive equations for tensile strength have been reported ${ }^{[33]}$ and can be used to present a qualitative analysis regarding the adhesion between the filler and the polyester. The volume fraction and the projected area fraction can be related by the equation of Nicolais and Narkis.

$$
\sigma_{\mathrm{c}}=\sigma_{\mathrm{m}}\left[1-K \phi^{2 / 3}\right]
$$

where $\sigma_{\mathrm{c}}$ and $\sigma_{\mathrm{m}}$ are the tensile strengths of the composite and the polymer matrix respectively and $\phi$ is the volume fraction of the filler. The parameter, $K$, in the model accounts for the adhesion between the filler and the matrix. The theoretical value of $K$ for the extreme case of poor adhesion is 1.21. A value of $K$ lower than the theoretical 1.21 indicates some adhesion. Assuming a particle density of hydroxyapatite and polyester to be $3.1 \mathrm{~g} / \mathrm{cm}^{3}$ and $1.2 \mathrm{~g} / \mathrm{cm}^{3}$ respectively, the $K$ value (Equation (1)) is close to 1.0 for the PBS and 30\% HA blend.

SEM micrographs (see below) indicate that hydroxyapatite and chitosan are dispersed in the continuous polyester phase. An increase in particle size and content results in the reduction of debonding stress due to the formation of micropores. The amount of debonded particles in the matrix, which determines the pore concentration, is a function of particle diameter; the higher the particle diameter, the lower the debonding stress. ${ }^{[34]}$ For these materials, failure occurs immediately following the onset of debonding, and the tensile strength equals the minimum debonding stress. ${ }^{[32]}$ Chitosan/PCL and chitosan/PBS samples with hydroxyapatite displayed a brittle fracture behavior, while chitosan/PBTA with hydroxyapatite displayed a uniform yield. PBTA has very low crystallinity compared to the other polyesters and retains some ductility even at high filler contents.

The lack of reinforcing ability of hydroxyapatite with synthetic polymers has been attributed to the lack of chemical interaction of hydroxyapatite with the polymer. ${ }^{[9,35,36]}$ In some instances, coupling agents were used to achieve improved strength. ${ }^{[37-39]}$ In other instances, innovative 
processing techniques have been used to improve strength. ${ }^{[40,41]}$ The modulus values obtained in this study are in the lower bounds of the properties of bone whose modulus have been reported to range up to $20 \mathrm{GPa}^{[42,43]}$ and could be adequate for minor load bearing applications. Hydrostatic extrusion and oriented molding could be two alternative processing techniques to increase properties further.

The values in Table 5 are further reduced because of the added effect of plasticizer, which reduces both the stress and modulus. Bergmann and Owen ${ }^{[17]}$ also observed weak adhesion between hydroxyapatite and polyhydroxybutyrate and poly(hydroxybutyrate-co-valerate). Addition of hydroxyapatite had negligible effect on the modulus, except in the case of chitosan/PCL blend, where it decreased. This could be due to a combination of lack of reinforcing ability of hydroxapatite due to lack of chemical interaction with the composite as well as the effect of the added plasticizer.

\section{Morphology}

The cryogenically-fractured and tensile-stretched specimen cross-section is shown in Figure 3 and 4. In general, a tensile-stretched specimen cross-section has cavities in two ranges of dimension: one set has diameters less than $4.0 \mu \mathrm{m}$ and the other has diameters greater than $4.0 \mu \mathrm{m}$. Hydroxyapatite crystals have diameters of approximately $3.0 \mu \mathrm{m}$. The smaller dimension cavities are more numerous. Many of the cavities have dimensions lower than $3.0 \mu \mathrm{m}$, some as low as $0.5 \mu \mathrm{m}$. This could be due to the result of break-down of hydroxyapatite crystals during the compounding process. For all the blends compounded with the hydroxyapatite crystals, it was observed that hydroxyapatite crystals are well distributed within the matrix.

The distribution of the hydroxyapatite crystals in the polymer matrix is best visualized by observing the tensilefractured surface in blend with pure polyester (PBS) (Figure 4a). The agglomeration of hydoxyapatite crystals is evident since they have dimensions much larger than those observed in blends containing chitosan and polyesters. $^{[24]}$ Similar observations has been reported by Bergmann and Owen ${ }^{[17]}$ in composites of hydroxyapatite and polyhydroxybutyrate and poly(hydroxybutyrate-covalerate). One reason for the agglomeration in our system could be due to the effect of stresses developed during processing. Composites containing chitosan, polyester, and hydroxyapatite had a much higher viscosity (due to increased filler content), and, hence, the stresses generated were higher than the blend containing hydroxyapatite and PBS. The higher stresses may have resulted in the deagglomeration of the hydroxyapatite crystals in these blends. Another observation is that hydroxyapatite crystals are actually visible in the composite (Figure 4a) with pure polyester as opposed to blends containing chitosan and

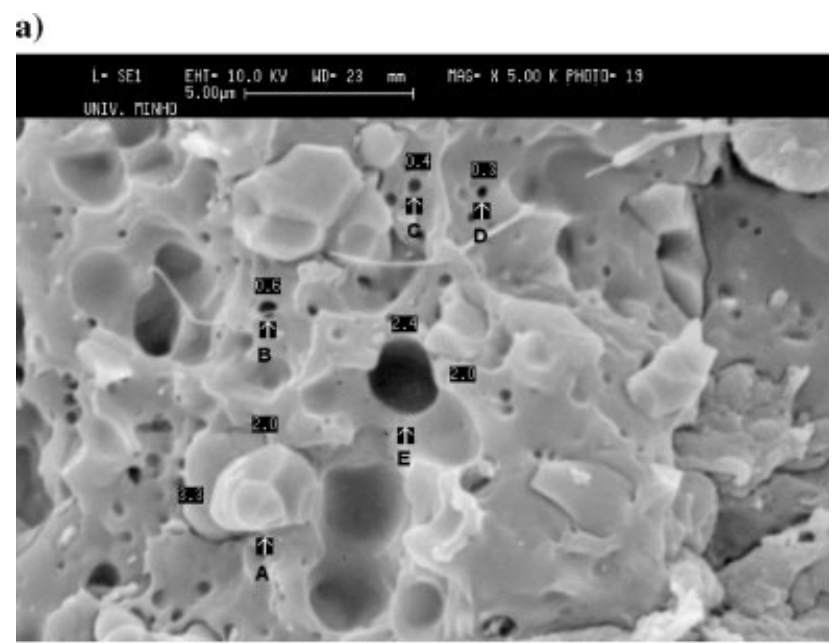

b)

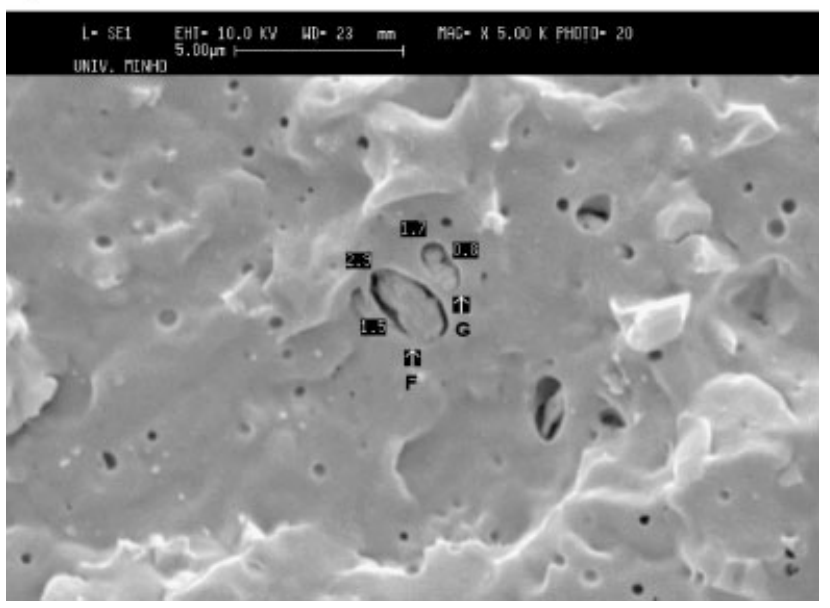

Figure 3. $17.5 \%$ chitosan, $52.5 \%$ PBS and $30 \%$ hydroxyapatite (a) tensile fractured and (b) cryogenically fractured. A: $3.3 \times$ $2.0 \mu \mathrm{m}$; B: $0.6 \mu \mathrm{m}$; C: $0.4 \mu \mathrm{m}$; D: $0.3 \mu \mathrm{m}$; E: $2.4 \times 2.0 \mu \mathrm{m}$; F: $1.5 \times 2.9 \mu \mathrm{m} ; \mathrm{G}: 1.7 \times 0.8 \mu \mathrm{m}$.

polyesters, where predominantly cavities without the particles are visible. One possible explanation is that pure polyester undergoes shrinkage that results in some adhesion with the hydroxyapatite crystals preventing complete detachment. With the presence of chitosan in the blend, the polyester/chitosan matrix undergoes minimal shrinkage and results in debonding. This also explains the fact that when hydroxyapatite crystals are added, only pure polyester (PBS) experienced an increase in the tensile modulus. Clements and Mas ${ }^{[44]}$ presented expressions from wherein modulus reinforcement can be estimated. For materials that debond and cause voids, the reinforcement factor is typically less than 1.0, irrespective of the aspect ratio of the filler.

The hydroxyapatite crystals have minimal adhesion to the polymer matrix, as is evident from the extensive debonding and the smooth surfaces of the cavities. The number of cavities believed to be as a result of hydroxyapatite 
a)

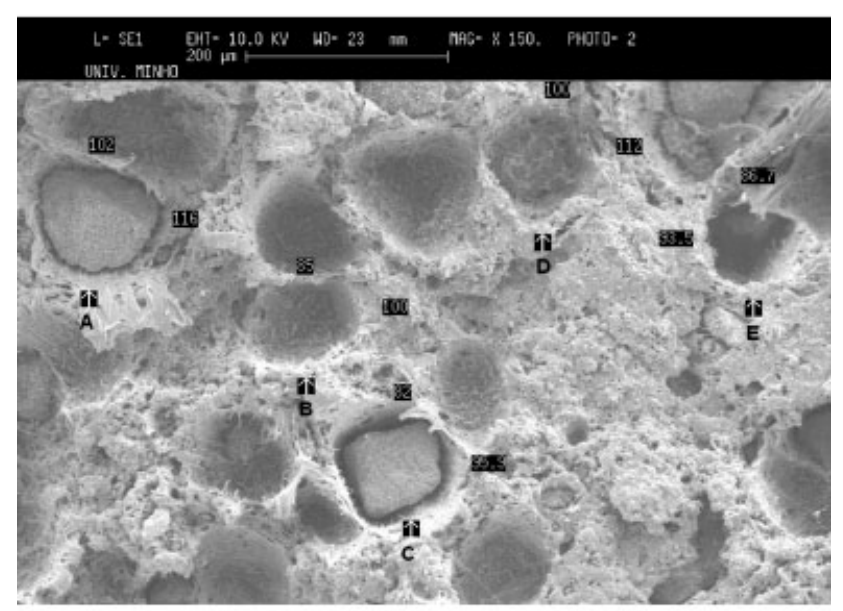

b)

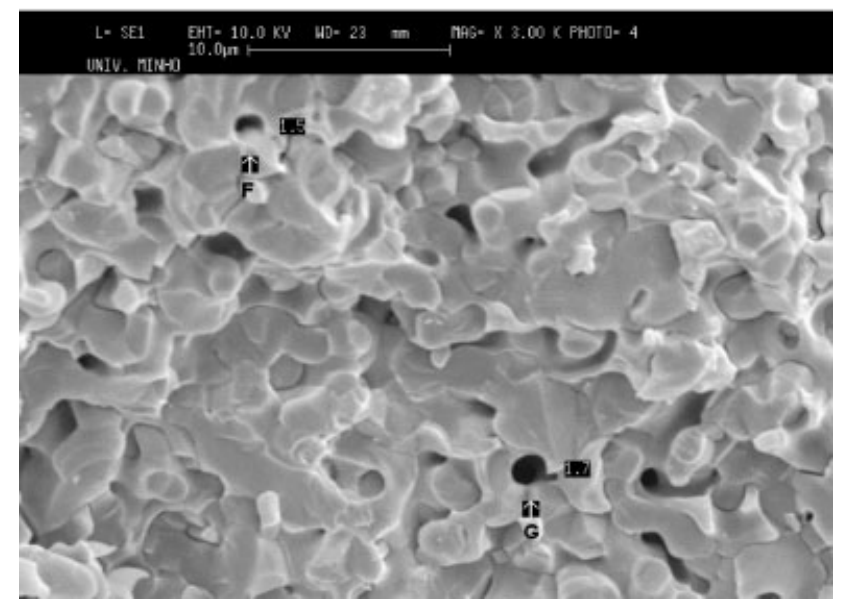

Figure 4. $70 \%$ PBS and $30 \%$ hydroxyapatite (a) tensile fractured and (b) cryogenically fractured. A: $102.0 \times 116.0 \mu \mathrm{m}$; B: $85.0 \times 100.0 \mu \mathrm{m}$; C: $82.0 \times 95.9 \mu \mathrm{m}$; D: $100.0 \times 112.0 \mu \mathrm{m}$; E: $93.5 \times 86.7 \mu \mathrm{m} ; \mathrm{F}: 1.5 \mu \mathrm{m} ; \mathrm{G}: 1.7 \mu \mathrm{m}$.

crystals is greater than those due to chitosan. As seen in Figure 3, the cavities generated in the tensile-fractured and cryogenically-fractured samples are due to hydroxyapatite. The number of cavities in the tensile-fractured surface is higher than those in the cryogenically-fractured surface. This is probably because chitosan has greater adhesion to the polyester matrix than hydroxyapatite has to the polyester and chitosan matrix. This supports the data from tensile tests that indicate a sharp drop in the tensile strength as hydroxyapatite is added as failure occurs at the initiation of debonding which happens at a lower stress with hydroxyapatite in the blend. Hence, it can be concluded that there is no chemical bonding between the hydroxyapatite crystals and the matrix. It appears that the polymer/chitosan simply flowed around the hydroxyapatite crystals. This could be one reason for minimal modulus reinforcement due to the added hydroxyapatite crystals. a)

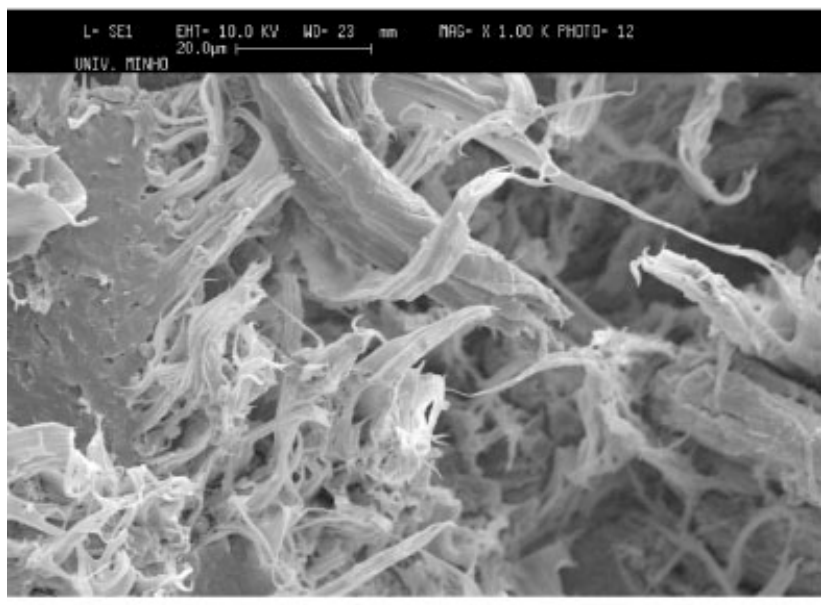

b)

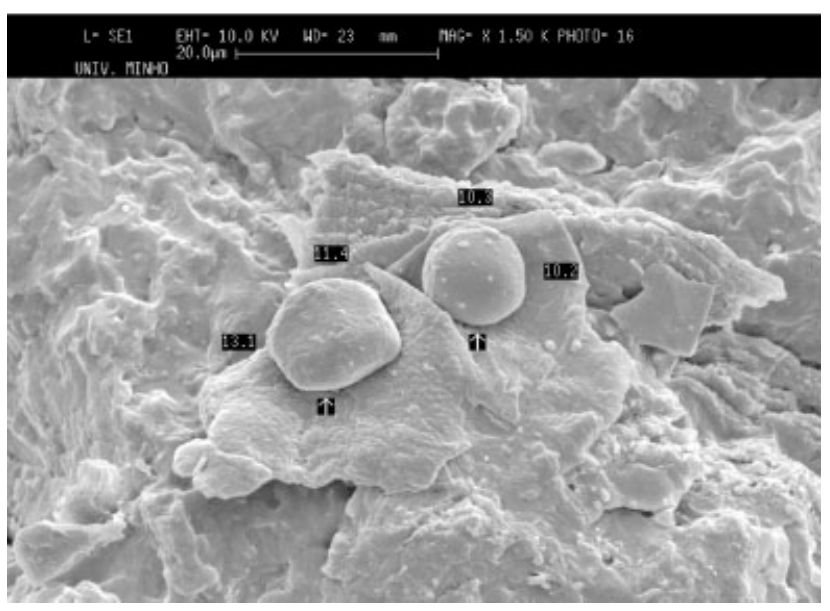

Figure 5. 35\% chitosan, 35\% PBTA and 30\% hydroxyapatite (a) tensile fractured, and (b) brittle fracture.

The surfaces of tensile fractured specimens show the typical appearance of brittle failure without visible plastic strain. The only exception is blend with the PBTA, which displayed some plastic deformation (Figure 5a). This is probably due to the low crystallinity of the polyester. The surface appears ductile-like with evidence of deformation and stretching of the matrix with submicron size fibrils. For the remaining materials, the morphology is relatively flat with minimal stretching of the matrix. During loading of the composite, deformation is sustainable until failure of the hydroxyapatite crystals occurs (due to debonding) and leads to stress overload of the remaining matrix. The tensile strength is lower than the similar blend composition without hydroxyapatite crystals because of the reduced cross-section area caused by the detached particles.

The cryogenically-fractured surface of all hydroxyapatite containing composites breaks in a brittle manner with 
little stretching of the matrix (Figure 5(b)). The filler content (chitosan and hydroxyapatite) in some cases are as high as $65 \%$, and plastic deformation is not observed on the surface of the fractured specimen. No hydroxyapatite crystals that are bare in the matrix (i.e., have no polymer matrix on them) are observed. Also, the failure of hydroxyapatite particle at the fracture surface is not evident. The absence of bare hydroxyapatite crystals or breaking off at the fracture surface indicates no adhesion of matrix to the hydroxyapatite and results in crystal pull-out during the fracture process.

\section{Wide-Angle X-Ray Scattering}

Representative WAXS patterns on some selected PCL- and PBS-based materials are shown in Figure 6a and 6b, respectively. In the first case, two main diffractions, at $2 \theta$ around 21 and $23^{\circ}$, attributed to the (110) and (200) planes in PCL are detected. ${ }^{[45]}$ The inclusion of HA did not influence the position of the two diffraction peaks of PCL (Figure 6a).

The diffraction diagrams for the PBS-based injection moulded parts (Figure $6 b$ ) display a peak at $2 \theta \approx 19.3^{\circ}$, assigned to the (11-1) and (002) planes, a peak of (110) at $2 \theta \approx 22.2^{\circ}$, with a shoulder at lower angles (better defined in the blends and composites) associated with the (012) planes, a peak of $(12-1)$ at $2 \theta \approx 25.9^{\circ}$ and a peak of $(111)$ at $2 \theta \approx 29^{\circ}$. An electron diffraction study showed that PBS chains crystallize in monoclinic crystal lattice, with $a=$ $0.523 \mathrm{~nm}, b=0.908 \mathrm{~nm}, c=1.079 \mathrm{~nm}$ and $\beta=123.87^{\circ} .{ }^{[46]}$ It can be seen in Figure $6 \mathrm{~b}$ that the position of the diffraction peaks is not altered with the introduction of chitosan or HA, as observed previously for the PCL system. Moreover, the half-widths of the two main diffraction peaks are maintained, indicating that the PBS crystal sizes do not change significantly with the introduction of HA. Only the intensity of the peaks is altered due to the loss of total crystallinity (with the blending with chitosan), or the intensity of the signal is strongly depressed in the case of the composites due to the strong diffraction of the HA crystals.

\section{Conclusion}

Chitosan and hydroxyapatite, an important biomaterial, can be melt blended with several biodegradable polyesters to produce materials with a range of acceptable properties. ${ }^{[4]}$ However, the addition of high volume fraction of fillers (both chitosan and hydroxyapatite) led to processing difficulties that made for poor dispersion, particularly for the HA in the composite. This coupled with the lack of adhesion of $\mathrm{HA}$ to the matrix led to reduced mechanical properties over blends of chitosan and polyester. ${ }^{[2]}$ Thus alternative processing techniques ${ }^{[37-41]}$ or the use coupling agents or the functionalization of the ceramic needs to be considered
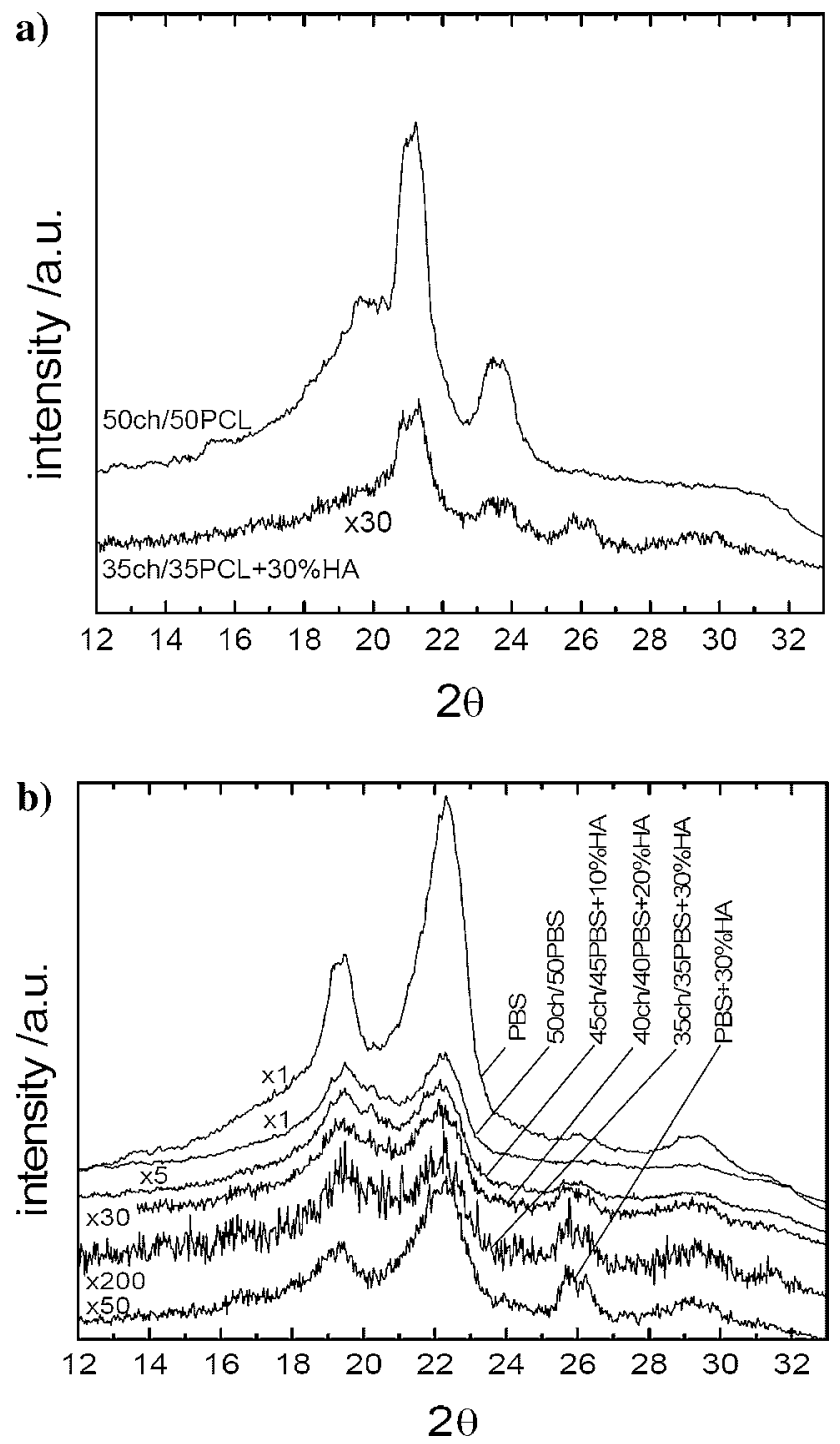

Figure 6. WAXS patterns of some PCL-based samples (a) and PBS-based samples (b), where the effect of the addition of HA is investigated. Some patterns were obtained by multiplying the original data by the values indicated near the corresponding lines, for better visualization.

to improve on the properties since the current properties are the lower bound of what is reported for bone.

Addition of HA to chitosan/PLA blends decreased the glass transition temperature as well as the temperature of the onset of crystallization. Melt compounded and injection molded composites of HA, chitosan, and synthetic aliphatic polyester displayed a skin core morphology. The filler domains tend to be enclosed in the inner regions of mouldings, confirming the observation that the continuous phase consists of polyester and the dispersed phase is composed of chitosan/hydroxyapatite domains. Cryogenically- and tensile-fractured surfaces of blends containing hydroxyapatite show extensive debonding, primarily of hydroxyapatite 
crystals, indicating poor adhesion between the hydroxyapatite and the chitosan/polyester matrix. This is manifested in reduced tensile strength and tensile modulus of these blends. The diffraction peaks observed using WAXS, are unaffected by the addition of the fillers. The morphological and mechanical properties indicate that the chitosan, ceramic, and polyester are phase-separated systems.

Acknowledgements: L. F. Boesel acknowledges Fundação Coordenação de Aperfeiçoamento de Pessoal do Ensino Superior (CAPES - Brasília, Brazil) for the PhD grant. MB would like to thank FLAD (Fundação Luso-Americana para o Desenvolvimento) for generous support of sabbatical funds towards this research. Financial support for this work was also provided by FCT through the POCTI and FEDER programs and by the EU Integrated Project GENOSTEM (Adult Mesenchymal Stem Cells Engineering for connective tissue disorders: from the bench to the bed side).

[1] R. A. A. Muzzarelli, "Enzymatic synthesis of Chitin and Chitosan", in: Chitin, Pergamon Press, Oxford 1977, pp. 517.

[2] M. N. V. Ravi Kumar, React. Funct. Polym. 2000, 46, 1.

[3] M. F. A. Goosen, "Applications of Chitin and Chitosan", Technomic Publishing Co. Inc., Pennsylvania 1997.

[4] I. Engleberg, J. Kohn, Biomaterials 1991, 12, 292.

[5] B. D. Ratner, A. S. Hoffman, F. J. Schoen, J. E. Lemons, "Biomaterials Science: An Introduction to Materials in Medicine", Academic Press 1996.

[6] C. M. Muller-Mai, S. I. Stupp, C. Voigt, U. Gross, J. Biomed Mater Res. 1995, 29, 9.

[7] J. T. Edwards, J. B. Brunski, H. W. Higuchi. J. Biomed Mater Res. 1997, 36, 454.

[8] K. De Groot, J. Ceram. Soc Jpn. 1991, 99, 943.

[9] S. Deb, M. Wang, K. E. Tanner, W. Bonfield, J. Mater. Sci. Mater. Med. 1996, 7, 191.

[10] J. Huang, L. Di Silvio, M. Wang, K. E. Tanner, W. Bonfield, J. Mater. Sci. Mater. Med. 1997, 8, 775.

[11] M. Wang, R. Joseph, W. Bonfield, Biomaterials 1998, 19, 2357.

[12] C. C. C. P. Verheyen, J. R. de Wijn, C. A. van Blitterswijk, K. de Groot, J. Biomed. Mater. Res. 1992, 26, 1277.

[13] I. Kazuhiko, A. Hiroki, N. Nobuo, M. Sadao, F. Kotaro, J. Biomed. Mater. Res. 1992, $26,937$.

[14] F. C. M. Driessens, M. G. Boltong, O. Bermudez, J. A. Planell, M. P. Ginebra, J. Biomed. Mater. Res. 1994, 28, 164.

[15] P. Cheang, K. A. Khor, Mater. Sci. Eng. A 2003, 345, 47.
[16] Z. B. Luklinska, W. Bonfield, J. Mater. Sci. Mater. Med. 1997, 8, 379.

[17] A. Bergmann, A. Owen, Polym. Int. 2003, 52, 1145.

[18] C. M. Vaz, R. L. Reis, A. M. Cunha, Biomaterials 2002, 23, 629.

[19] R. A. Sousa, J. F. Mano, R. L. Reis, A. M. Cunha, M. J. Bevis, Polym. Eng. Sci. 2002, 42, 1032.

[20] Q. Liu, J. R. de Wijn, C. A. van Blitterswijk, J. Biomed. Mater. Res. 1998, 40, 490.

[21] V. Midy, M. Dard, E. Hollande, J. Mater. Sci. Mater. Med. 2001, 12, 259.

[22] D. Heymann, J. Guichex, A. V. Rousselle, Histol. Histopathol. 2001, 16, 37.

[23] Y. Shirakata, S. Oda, A. Kinoshita, S. Kikuchi, H. Tsuchioka, I. Ishikawa, J. Periodontal. 2002, 73, 1043.

[24] V. M. Correlo, L. F. Boessel, M. Bhattacharya, J. F. Mano, N. M. Neves, R. L. Reis, Mater. Sci. Eng. A 2005, 403, 57.

[25] K. Kesenci, L. Fambri, C. Migliaresi, E. Piskin, J. Biomater. Sci., Polym. Ed. 2000, 11, 617.

[26] J. Y. Hao, M. L. Yuan, X. M. Deng, J. Appl. Polym. Sci. 2002, $86,676$.

[27] T. Honma, T. Senda, Y. Inoue, Polym. Int. 2003, 52, 1839.

[28] H. L. Chen, L. J. Li, T. L. Lin, Macromolecules 1998, 31, 2255.

[29] D. W. Van Krevelen, "Properties of Polymers", Elsevier, Amsterdam 1990.

[30] D. H. S. Ramkumar, M. Bhattacharya, Polym. Eng. Sci. 1998, 38, 1426.

[31] K. Jamshidi, S. H. Hyon, Y. Ikada, Polymer 1988, 29, 2229.

[32] I. L. Dubnikova, V. G. Oshmyan, A. Ya. Greenberg, J. Mater. Sci. 1997, 32, 1613.

[33] L. E. Nielsen, "Mechanical Properties of Polymers and Composites", Marcel Dekker, New York 1974.

[34] N. D. Albelora, P. Mele, Polym. Eng. Sci. 1997, 37, 1712.

[35] K. Wang, S. Deb, W. Bonfield, Mater. Lett. 2000, 44, 119.

[36] K. Wang, W. Bonfield, Biomaterials 2001, 22, 1311.

[37] R. A. Sousa, R. L. Reis, A. M. Cunha, M. J. Bevis, J. Mater Sci. Mater. Med. 2003, 14, 475.

[38] R. A. Sousa, R. L. Reis, A. M. Cunha, M. J. Bevis, J. Appl. Polym. Sci. 2002, 86, 2866.

[39] C. M. Vaz, R. L. Reis, A. M. Cunha, Biomaterials 2003, 23, 629.

[40] M. Wang, N. H. Ladizesky, K. E. Tanner, I. M. Ward, W. Bonfield, J. Mater. Sci. 2000, 35, 1023.

[41] N. H. Ladizesky, I. M. Ward, W. Bonfield, Polym. Adv. Technol. 1997, 8, 496.

[42] J. Y. Rho, L. Kuhn-Spearing, P. Zioupos, Med. Eng. Phys. 1998, 20, 92.

[43] J. Y. Rho, R. B. Ashman, C. H. Turner, J. Biomech. 1993, 26, 111.

[44] B. E. Clements, E. M. Mas, J. Appl. Phys. 2001, 90, 5522.

[45] Y. Chatani, Y. Okita, H. Yadokoro, Y. Yamashita, Polym. J. (Tokyo) 1970, 1, 555.

[46] K. J. Ihn, E. S. Yoo, S. S. Inn, Macromolecules 1995, 28, 2460. 